\title{
Molecular characterization of an outbreak of enterovirus-associated meningitis in Mossel Bay, South Africa, December 2015- January 2016
}

Heidi Smuts ${ }^{1 *}$ (D) Sarah Cronje ${ }^{2}$, Juno Thomas ${ }^{3}$, Delene Brink ${ }^{4}$, Stephen Korsman ${ }^{1}$ and Diana Hardie ${ }^{1}$

\begin{abstract}
Background: Human enteroviruses (HEVs) are common causal agents of aseptic meningitis in young children. Laboratory and syndromic surveillance during December 2015 and January 2016 noted an unusually high number of paediatric aseptic meningitis cases at a hospital in Mossel Bay, Western Cape Province, South Africa. HEV was detected in clinical samples, prompting an outbreak investigation.

Methods: Epidemiological investigations were conducted to ascertain possible linkage between cases. Amplification, sequencing and phylogenetic analysis of the 5'UTR and VP1 regions was undertaken to determine the HEV serotype associated with the outbreak as well as other cases of aseptic meningitis in the area in the preceding 6 weeks.

Results: Over the 2-month period, 63 CSF samples were available for testing. A total of 43 outbreak cases (68.3\%) were observed, and the 26 (60.5\%) that could be typed were coxsackie virus A9 (CVA9). Children attending three crèche facilities were epidemiologically linked, accounting for $60.5 \%$ (26/43) of the CVA9 cases. The majority of patients were under 10 years of age $(55 / 63,87.3 \%)$ and there was a male predominance $(66 \%)$. Nucleotide sequence analysis of the 5'UTR and VP1 regions identified 2 lineages of CVA9 co-circulating during the outbreak, although the VP1 capsid protein sequence was identical as all nucleotide differences were synonymous. There was a unique isoleucine at position 64 and all outbreak viruses had a valine to threonine change in the hypervariable BC loop of VP1. Other HEV types circulating in the preceding period were echovirus $30(n=4)$, echovirus $5(n=3)$ and 1 each of echovirus 6, echovirus 9 and echovirus 15.
\end{abstract}

Conclusion: CVA9 was identified as the pathogen responsible for the large outbreak of aseptic meningitis, with 2 distinct co-circulating lineages.

Keywords: Aseptic meningitis, Coxsackie virus A9, Outbreak, South Africa

\section{Background}

Human enteroviruses (HEVs) are ubiquitous and cause an array of clinical syndromes ranging from asymptomatic infections, in about $80 \%$ of cases, to more severe illnesses including respiratory infection, acute haemorrhagic conjunctivitis, hand- foot-and-mouth disease, neonatal sepsis,

\footnotetext{
* Correspondence: Heidi.Smuts@uct.ac.za

${ }^{1}$ Division of Medical Virology, Department of Pathology, Faculty of Health Sciences, University of Cape Town, South Africa and the National Health Laboratory Service, Anzio Road, Observatory, Cape Town 7925, South Africa Full list of author information is available at the end of the article
}

myocarditis, paralytic disease, encephalitis and aseptic meningitis $[1,2]$. The virus is spread from person to person most commonly via the faecal-oral route and less frequently through respiratory droplets [3, 4]. Transmission often occurs within the family, in schools, hostels and chronic care facilities $[1,4]$. Community and nosocomial spread is also reported, particularly where there is overcrowding $[3,5]$.

Most HEV infections occur in the summer/autumn months in temperate climates and throughout the year in tropical regions $[4,6]$. Usually only a few serotypes

(c) The Author(s). 2018 Open Access This article is distributed under the terms of the Creative Commons Attribution 4.0 International License (http://creativecommons.org/licenses/by/4.0/), which permits unrestricted use, distribution, and 
predominate in each HEV season and these can lead to outbreaks of a localised or more widespread nature.

HEVs belong to the family Picornaviridae, genus Enterovirus and are classified into 4 species (A, B, C and $D)$ based on neutralizing assays, sequence data and analysis of the virus capsid VP1 gene [7-9]. The VP1 capsid protein is exposed on the outer surface of the virion, has specific epitopes, particularly in the $\mathrm{BC}$ loop, that elicit type-specific neutralising antibodies and are primarily responsible for defining the serotype $[1,6,10-12]$. Laboratory diagnosis using molecular technologies enables rapid detection of HEV and has largely replaced the more labour intensive virus culture and isolation methods. Reverse transcription PCR (RT-PCR) diagnostic methodologies target the most conserved region of the HEV genome, 5' untranslated region (5'UTR), while typing for the investigation of outbreak and clinical disease associations usually targets the VP1 gene.

Aseptic meningitis is a self-limiting illness occurring in adults and children, with neonates most at risk of severe systemic illness. HEVs are the most common causal agent and association is inferred by the detection or isolation of virus from the cerebrospinal fluid [13].

Numerous viral meningitis outbreaks associated with HEVs have been reported in South Africa. The most comprehensive study from Cape Town during 19811989 identified 5 major episodes involving over 1400 cases with echovirus 4, echovirus 9 and coxsackie virus A9 (CVA9) most commonly identified [14]. Other reports include an outbreak of echovirus 3 at a summer camp in 2001 involving 15 children [15], 9 cases of enterovirus 84 in the small town of Ladismith in 2009 [16] and an outbreak of echovirus 4 in 23 children from the Tshwane region in 2010-2011 [17].

This study reports the epidemiology of a large outbreak of aseptic meningitis associated with enteroviruses in Mossel Bay, Western Cape Province, South Africa from December 2015-January 2016.

\section{Objectives}

The objective of this study was to determine the molecular epidemiology of HEVs in the CSF of patients presenting with aseptic meningitis in Mossel Bay, South Africa, over a 2-month period.

\section{Methods}

\section{Patients and samples}

Mossel Bay is coastal town in the Western Cape Province, South Africa, located midway between Cape Town and Port Elizabeth. There is one municipal and one private hospital and numerous educational and crèche facilities. During the study period schools closed on 12th December 2015 for annual summer vacation and reopened on 13th January 2016.
In mid-January 2016 local healthcare workers noticed an increase in young children presenting at a private sector hospital (Life Bay View Private Hospital) with clinical manifestations and laboratory findings suggestive of aseptic meningitis. The increase was from 3 to 7 cases weekly preceding the outbreak to $4-6$ cases daily during the outbreak period. Cerebrospinal fluid (CSF) samples were collected from hospitalised patients and tested at a private laboratory (PathCare, in George), where an HEV was identified as the causative pathogen. The Western Cape Department of Health was notified of the suspected outbreak, prompting an epidemiological investigation to ascertain possible links between cases, implementation of control measures, and health promotion activities. Demographic data was collected on all HEV-positive patients hospitalised with symptoms of aseptic meningitis from 1st December 2015 to the first week in February 2016 in order to place the outbreak in context.

CSF samples from aseptic meningitis cases were referred to the PathCare George laboratory and screened using the Meningitis/Encephalitis (ME) Panel (BIOFIRE ${ }^{\circ}$ FILMARRAY ${ }^{\circ}$ ) which detects 14 relevant bacterial, viral and yeast pathogens. Samples that were positive for HEV and still stored at the PathCare George laboratory were sent to the NHLS Molecular Virology diagnostic laboratory in Cape Town for HEV typing.

\section{Case definitions}

A confirmed case of aseptic meningitis was defined as any person admitted to the Life Bay View Private Hospital in Mossel Bay between 1st December 2015 and 3rd February 2016 with a history of acute onset of severe headache, nausea and/or vomiting and fever with compatible laboratory findings on CSF analysis.

\section{RNA extraction}

Total nucleic acid was extracted from $500 \mu \mathrm{l}$ CSF using the NucliSENS easyMag (bioMerieux SA, Lyon, France) and eluted in $50 \mu$ l elution buffer.

\section{HEV typing by VP1, VP2 and 5'UTR amplification}

cDNA was generated with random primers using the RevertAid First Strand cDNA synthesis kit (Thermo Scientific, Lithuania), as per manufacturer's instructions.

Species-specific nested PCRs were used to amplify a region of the VP1 gene of EV-A and EV-B using primers from McWillliam Leitch et al. [18], while the VP2 gene was used to detect EV-C [19], generating PCR fragments of $784 \mathrm{bp}, 1085 \mathrm{bp}$ and $406 \mathrm{bp}$, respectively. Samples that were still negative after species- specific amplification were investigated by amplification of a $498 \mathrm{bp}$ fragment of the 5'UTR region [18]. The PCR was performed in a $50 \mu \mathrm{l}$ reaction containing $5 \mu \mathrm{l} \mathrm{cDNA}, 15 \mathrm{mM}$ Tris-HCL (pH 8), $50 \mathrm{mM} \mathrm{KCl}, 1.5 \mathrm{mM} \mathrm{MgCl}_{2}, 0.2 \mathrm{mM}$ dNTPs 
(ABgene, Epsom, UK), $50 \mathrm{pmol}$ of primers and $1.5 \mathrm{U}$ Supertherm Taq polymerase (JMR Holdings, Kent, UK). Amplification was as follows: $95^{\circ} \mathrm{C}$ for $3 \mathrm{~min}, 40$ cycles of $95^{\circ} \mathrm{C}$ for $15 \mathrm{~s}, 50^{\circ} \mathrm{C}$ for $25 \mathrm{~s}$ and $72^{\circ} \mathrm{C}$ for $35 \mathrm{~s}$ followed by $72{ }^{\circ} \mathrm{C}$ elongation for $7 \mathrm{~min}$. Nested amplification was the same, but with an annealing temperature of $55^{\circ} \mathrm{C}$. PCR products were visualised by electrophoresis through a $2 \%$ agarose gel, ethidium bromide staining and UV illumination.

\section{Sequencing}

PCR products were cleaned up using the Zymoclean Gel DNA Recovery kit (Zymo Research Corp. Irvine, California, USA) and sequenced directly with the BigDye terminator cycle sequencing kit (Applied Biosystems, Foster City CA, USA) using PCR-specific primers. Sequences were confirmed to be of HEV origin using BLASTn [20] and the Enterovirus Genotyping Tool Version 0.1 [21]. Sequences obtained were aligned with reference sequences obtained from the GenBank database and the NIAID Virus Pathogen Database and Analysis Resource (ViPR) [22] through the website "http:// www.viprbrc.org/" using BioEdit version 7.2.5 [23]. Additional HEV sequences from Cape Town (NHLS Virology Molecular Diagnostic Laboratory) and Johannesburg (National Institute for Communicable Diseases, NICD) were also included. Neighbour-joining phylogenetic trees were constructed in MEGA 6.06 using the maximum-likelihood algorithm with 1000 bootstrap re-sampling [24]. Highlighter plots were generated by Highlighter [25] using 5' UTR and VP1 aligned nucleotide and amino acid sequences to visualize individual sequence polymorphisms.

\section{Nucleotide accession numbers}

The 5'UTR and VP1 sequences reported in this study were deposited in the GenBank sequence database under accession numbers MH558061 - MH558083 and MH558084 MH558112, respectively. The raw nucleotide data is also available (Additional files 1 and 2).

\section{Results}

Epidemiological investigation during the 2-month period (1st December 2015 to 3rd February 2016) identified 63 laboratory-confirmed cases of HEV meningitis (Table 1). Forty-three $(68.3 \%)$ cases were associated with the outbreak as these could either be epidemiologically linked, and/or occurred after the reopening of schools on 13th January 2016. In addition, where typing was successful, CVA9 was linked to these outbreak cases $(26 / 43,60.5 \%)$ (see below). Accordingly, it was presumed that the 43 cases of the outbreak were caused by CVA9. In the remaining 20 cases no epidemiologically linkage could be established. These cases probably represented sporadic cases of aseptic meningitis, with different HEV types, occurring during the summer season when aseptic meningitis caused by HEVs is common. All patients were admitted to hospital. The demographic features of the laboratory-confirmed cases are shown in Table 1.

Epidemiological investigations showed that 3 crèches (A, B and C) were linked to 26 outbreak cases: 6 cases from crèche $A, 16$ cases from crèche $B$ and 4 cases from crèche $\mathrm{C}$. Of the remaining 17 cases, two were family members of crèche-related cases, and no definitive link to a crèche could be established for 15 cases. The epidemiological curve illustrating the background sporadic cases and progression of the outbreak is shown in Fig. 1.

The age of confirmed HEV-positive cases ranged from 10 days to 37 years with a median age of 3 years 9 months (Fig. 2). There was a predominance of males affected $(66.7 \%$; 42/63).

\section{HEV typing \\ VP1/VP2 typing}

CSF was available for typing in $51 / 63$ cases $(81 \%)$, of which the VP1 or VP2 region could be successfully amplified in 29 samples (56.9\%), with 24/29 (82.8\%) identified as HEV species B. The PCR products of the remaining samples were too weak to sequence. No HEV species $\mathrm{A}$ and $\mathrm{C}$ were detected. The Enterovirus Typing Tool and BLASTn analysis identified the majority of samples to be CVA9 ( $n=19 ; 79.2 \%$ ) followed by echovirus $5(\mathrm{n}=3 ; 12.5 \%)$ and one case each of echovirus 30 and echovirus 9 (4.2\%).

\section{5'UTR typing}

The 5'UTR primers were used to amplify samples negative for HEV species amplification $(n=22)$. Thirteen of the $22(59.1 \%)$ cases were successfully amplified, sequenced, and BLASTn analysis identified 6 CVB3 cases, 3 echovirus 16 cases, 2 echovirus 30 cases and one each of echovirus 15 and echovirus 6 (Table 1 and Fig. 1). Interestingly, 8/9 CVB3 and echovirus 16 positives were detected during the outbreak period. Further amplification and sequencing of the 5'UTR region from known CVA9 samples (typing based on VP1/VP2 analysis) and associated with the outbreak, showed that these samples either had a CVB3-like or echovirus 16-like 5'UTR suggesting that these may be recombinant viruses. The assumption was therefore made that the samples identified as CVB3 and echovirus 16 by 5'UTR sequencing were in fact CVA9. This is supported by phylogenetic analysis of the VP1 and 5'UTR (Fig. 3A and B).

\section{Phylogenetic analysis}

Phylogenetic analysis of the VP1 gene of CVA9 cases showed that the South African sequences clustered together and formed 2 lineages with a bootstrap value of $99 \%$. Lineage 1 clustered with sequences from contemporaneous 
Table 1 Demographics of the HEV-positive aseptic meningitis cases

\begin{tabular}{|c|c|c|c|c|}
\hline Patient & $\begin{array}{l}\text { Age Range } \\
\text { (years) }\end{array}$ & Place of permanent residence & Epidemiological link & HEV serotype \\
\hline 1501 & $0-4$ & NK & No school involvement & \\
\hline 9525 & $0-4$ & Mossel Bay & No school involvement & \\
\hline 9365 & $0-4$ & Mossel Bay & Unknown & E9 \\
\hline 0784 & $0-4$ & Pretoria & No school involvement & $\mathrm{E} 30^{*}$ \\
\hline 0780 & $0-4$ & Mossel Bay & No school involvement & \\
\hline 0785 & $0-4$ & Mossel Bay & Unknown & $\mathrm{E}^{*}$ \\
\hline 1502 & $0-4$ & NK & No school involvement & \\
\hline 0838 & $10-14$ & Witbank & No school involvement & E5 \\
\hline 0847 & $5-9$ & Pretoria & No school involvement & E5 \\
\hline 0864 & $0-4$ & Mossel Bay & No school involvement & \\
\hline 1503 & $10-14$ & NK & No school involvement & \\
\hline 1104 & $0-4$ & Middelburg & No school involvement & E5 \\
\hline 0947 & $5-9$ & Pretoria & Unknown & \\
\hline 2083 & $5-9$ & Riversdal & Unknown & CVA9 \\
\hline 2149 & $10-14$ & Kimberley & Unknown & $\mathrm{E} 30^{*}$ \\
\hline 2314 & $0-4$ & Mossel Bay & Unknown & CVA9/CVB3* \\
\hline 2319 & $0-4$ & Mossel Bay & Unknown & \\
\hline 2446 & $5-9$ & Douglas & Unknown & E15* \\
\hline 2572 & $5-9$ & Jan Kempdorp & Unknown & \\
\hline 2407 & $5-9$ & Bloemfontein & Unknown & E30 \\
\hline 3965 & $10-14$ & Mossel Bay & Unknown & CVA9 \\
\hline 4103 & $0-4$ & Mossel Bay & Unknown & \\
\hline 4751 & $0-4$ & Mossel Bay & Unknown & CVA9 \\
\hline 5012 & $0-4$ & Mossel Bay & A crèche & CVA9 \\
\hline 5018 & $0-4$ & Mossel Bay & Unknown & CVA9 \\
\hline 4809 & $0-4$ & Mossel Bay & A crèche & CVA9 \\
\hline 1601 & $0-4$ & Mossel Bay & A crèche & \\
\hline 4969 & $0-4$ & Mossel Bay & Unknown & CVA9/E16* \\
\hline 5081 & $5-9$ & Mossel Bay & Unknown & CVA9 \\
\hline 5084 & $0-4$ & Mossel Bay & Unknown & CVA9 \\
\hline 1602 & $10-14$ & Mossel Bay & C crèche & \\
\hline 5114 & $0-4$ & Mossel Bay & B crèche & CVA9 \\
\hline 5146 & $0-4$ & Mossel Bay & $\begin{array}{l}\text { B crèche } \\
\text { Sibling of } 4938\end{array}$ & CVA9 \\
\hline 5064 & $0-4$ & Mossel Bay & B crèche & CVA9/E16* \\
\hline 1603 & $0-4$ & NK & A crèche & \\
\hline 5088 & $0-4$ & Mossel Bay & B crèche & CVA9 \\
\hline 5100 & $0-4$ & Mossel Bay & B crèche & \\
\hline 5112 & $0-4$ & Mossel Bay & B crèche & CVA9/CVB3* \\
\hline 5145 & $0-4$ & Mossel Bay & B crèche & CVA9 \\
\hline 5157 & $0-4$ & Mossel Bay & B crèche & \\
\hline 1604 & $0-4$ & Mossel bay & B crèche & \\
\hline 5110 & $0-4$ & Mossel Bay & $\begin{array}{l}\text { B crèche } \\
\text { Child of } 5470\end{array}$ & CVA9 \\
\hline
\end{tabular}


Table 1 Demographics of the HEV-positive aseptic meningitis cases (Continued)

\begin{tabular}{|c|c|c|c|c|}
\hline Patient & $\begin{array}{l}\text { Age Range } \\
\text { (years) }\end{array}$ & Place of permanent residence & Epidemiological link & HEV serotype \\
\hline 4929 & $0-4$ & Mossel Bay & B crèche & CVA9 \\
\hline 4938 & $0-4$ & Mossel Bay & Sibling of 5146 & CVA9 \\
\hline 4962 & $0-4$ & Mossel Bay & B crèche & CVA9/CVB3* \\
\hline 4965 & $0-4$ & Mossel Bay & C crèche & CVA9 \\
\hline 1605 & $5-9$ & Mossel Bay & C crèche & \\
\hline 5408 & $10-14$ & Mossel Bay & Unknown & CVA9/ E16* \\
\hline 5411 & $10-14$ & Mossel Bay & Unknown & \\
\hline 5433 & $0-4$ & Mossel Bay & Unknown & CVA9/CVB3* \\
\hline 5470 & $30-40$ & Mossel Bay & Parent of 5110 & CVA9/CVB3* \\
\hline 5575 & $0-4$ & Mossel Bay & Unknown & CVA9/ CVB3* \\
\hline 5486 & $5-9$ & Mossel Bay & Unknown & \\
\hline 5557 & $0-4$ & Mossel Bay & $\begin{array}{l}\text { A crèche } \\
\text { Sibling of } 5488\end{array}$ & \\
\hline 5578 & $0-4$ & Mossel Bay & Unknown & CVA9 \\
\hline 4886 & $5-9$ & Mossel Bay & B crèche & CVA9 \\
\hline 4876 & $5-9$ & Mossel Bay & Unknown & \\
\hline 4869 & $0-4$ & Mossel Bay & Unknown & CVA9 \\
\hline 5488 & $5-9$ & Mossel Bay & $\begin{array}{l}\text { A crèche } \\
\text { Sibling of } 5557\end{array}$ & \\
\hline 1606 & $0-4$ & Mossel Bay & C crèche & \\
\hline 1607 & $5-9$ & Mossel Bay & B crèche & \\
\hline 1608 & $0-4$ & Mossel Bay & B crèche & \\
\hline 1609 & $0-4$ & Mossel Bay & B crèche & \\
\hline
\end{tabular}

*typing by 5'UTR sequencing and BLASTn analysis; E5- echovirus 5; E6- echovirus 6; E9- echovirus 9; E15- echovirus 15; E16- echovirus 16; E30-echovirus 30; CVA9coxsackie virus A9; CVB3- coxsackie virus B3

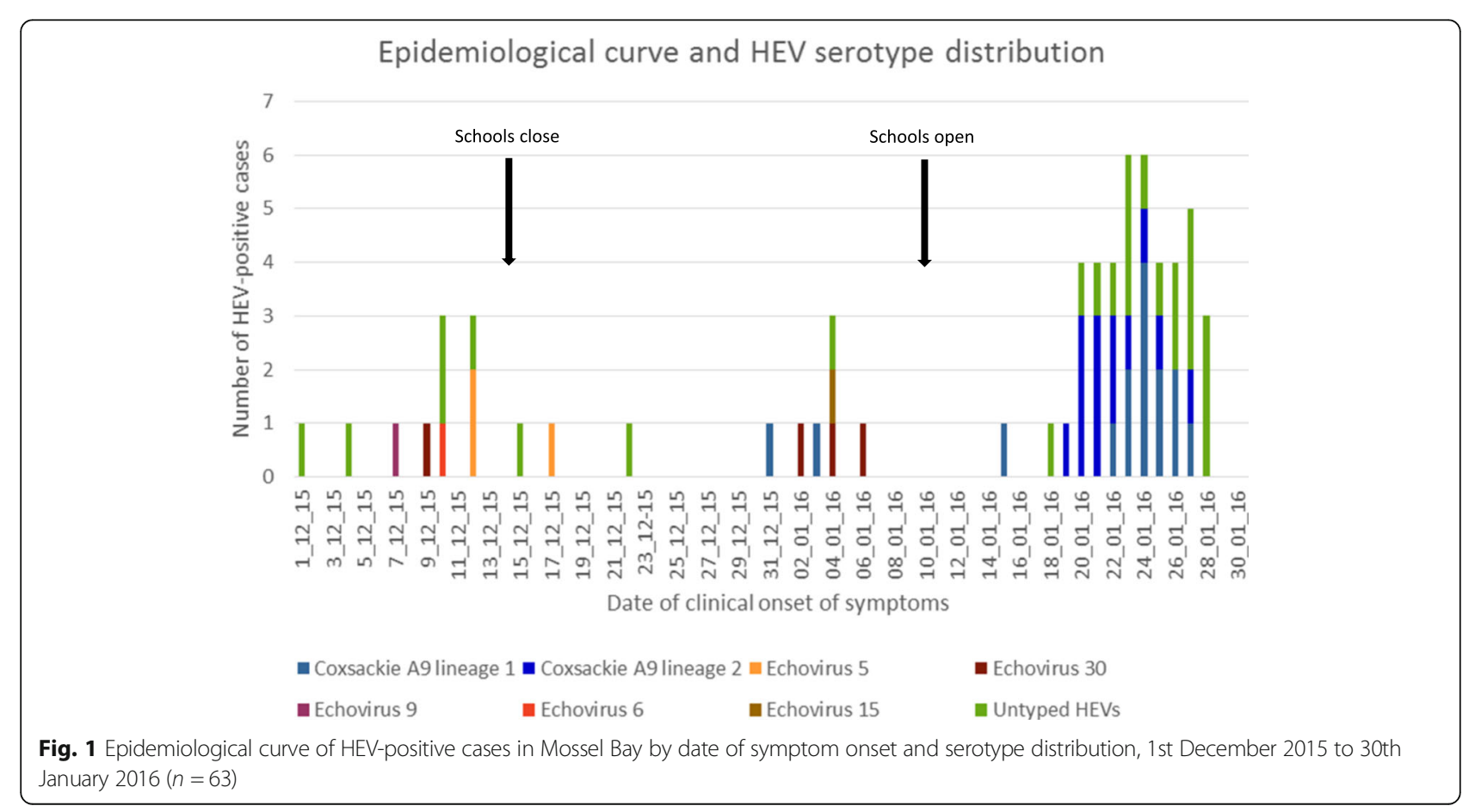




\section{Age distribution}

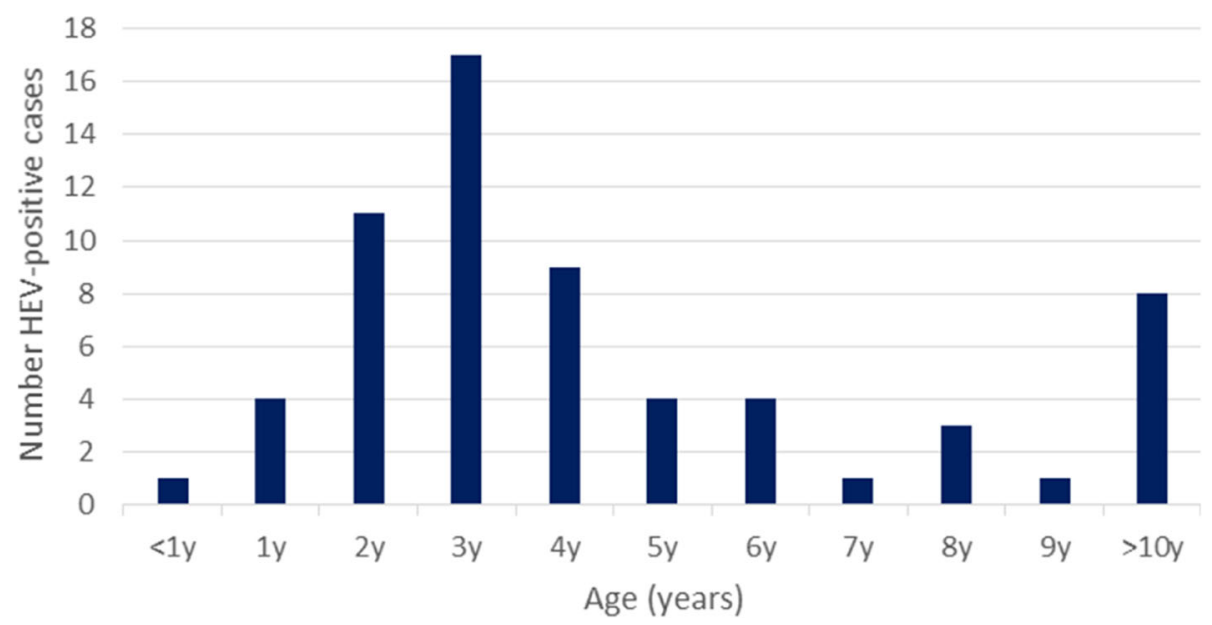

Fig. 2 Age distribution of HEV- positive aseptic meningitis cases $(n=63)$

infections from Cape Town and Johannesburg. However, 7/ 9 Mossel Bay sequences formed a distinct cluster. These included 6 cases from the crèche $B$ and 1 case with an unknown epidemiological link.

Lineage 2 contained only Mossel Bay sequences. They were from cases from crèches $A$ and $B$, as well as patients with unknown epidemiological links (Fig. 3A). Both lineages co-circulated during the outbreak (Fig. 1 and Fig. 3A). Interestingly, 2 siblings, one who attended $B$ crèche and the other a 10 day-old baby, had CVA9 that clustered with lineage 1 and lineage 2 , respectively (Fig. 3A with asterisk).

The phylogenetic tree of the 5'UTR region (Fig. 3B) also showed 2 lineages, as found in the VP1 phylogenetic tree (Fig. 3A). Lineage 1 samples had a CVB3-like 5'UTR, while lineage 2 had an echovirus 16-like 5'UTR (as determined by Blastn analysis).

\section{Sequence analysis of Coxsackie virus A9 lineages 5' UTR and VP1 nucleotide sequences}

The 5'UTR and VP1 nucleotide differences between the two lineages of CVA9 were compared using Highlighter plot. Lineage 2 had 8/417 (1.9\%) and 13/289 (4.5\%) nucleotide differences in the 5'UTR and VP1 region, respectively compared to lineage 1 (Fig. 4A and B). All nucleotide changes in the VP1 region were synonymous.

\section{VP1 amino acid sequences}

The VP1 amino acid sequences were identical for both lineages 1 and 2 and were also identical to the isolates from Cape Town (Fig. 5). All Mossel Bay sequences had a unique isoleucine at position 64 , while valine was present at this position in all other reference sequences, including the Griggs prototype (Fig. 5). A threonine replaced a valine within the $\mathrm{BC}$ loop (Fig. 5). The $\mathrm{BC}$ loop is one of them most exposed regions of the VP1 capsid protein.

\section{Discussion}

In this study we describe the molecular epidemiology of HEV associated with a large outbreak of aseptic meningitis in a small coastal town in the Western Cape Province, South Africa which occurred in the summer of 2015/2016. During the 2-month period (December 2015 and January 2016) numerous cases presented to hospital with aseptic meningitis, of which 63 were confirmed by a private diagnostic laboratory to be caused by an HEV. Enterovirus typing of CSF samples collected over this period showed the presence of multiple circulating HEV species, including echovirus 5, 6, 9, 15 and 30 in the weeks preceding the outbreak. As $60 \%$ of the cases that occurred during the outbreak period were typed as CVA9, it was presumed that this was the causal agent of the outbreak. The first CVA9 case presented on 31st December 2015 and a further 2 cases with no apparent epidemiological links presented 3 and 15 days later. However, a dramatic increase in cases was noted within a week after crèches and schools reopened (13th January 2016). It can be postulated that the return of children to a crowded environment may have facilitated the spread of the virus.

Crèches and preschool facilities are vulnerable to rapid spread of viruses transmitted via the faecal-oral route, including HEVs [26-28]. The maintenance of good personal and communal hygiene practices with the prompt disposal of faeces and soiled clothing, disinfection of contaminated surfaces and the frequent washing of hands may be challenging in such an environment. In 


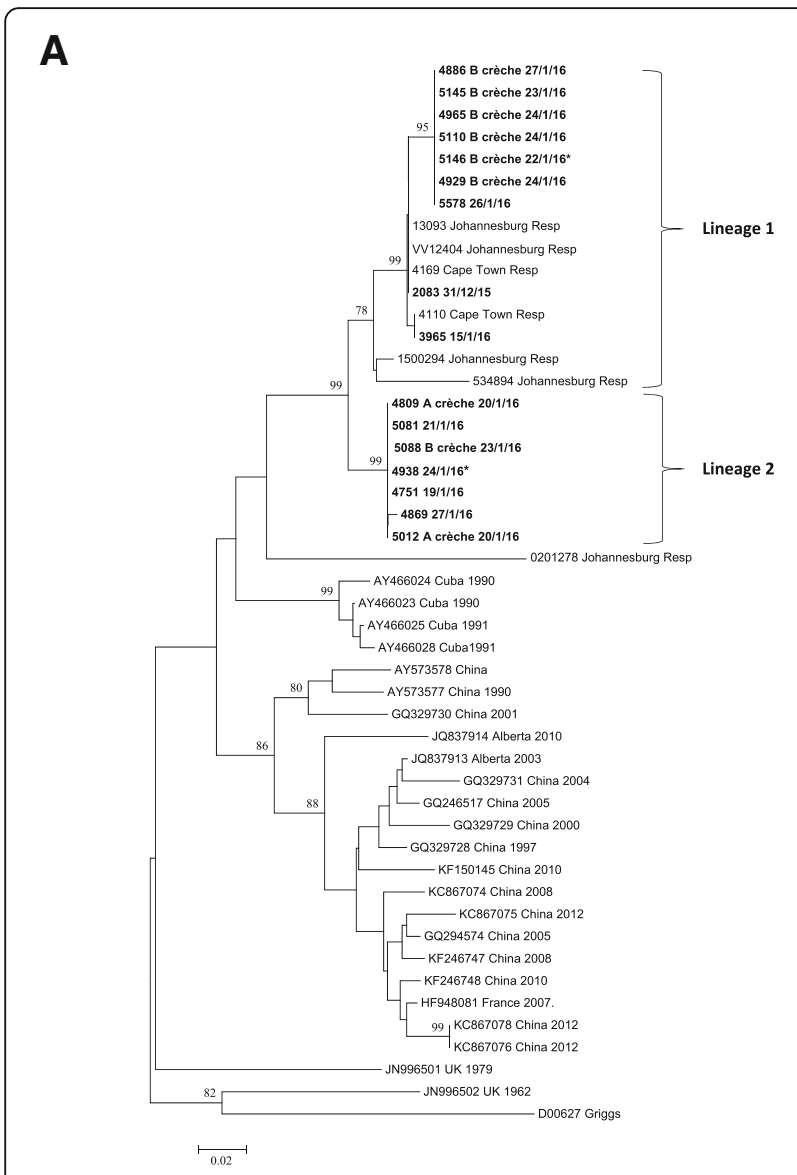

B

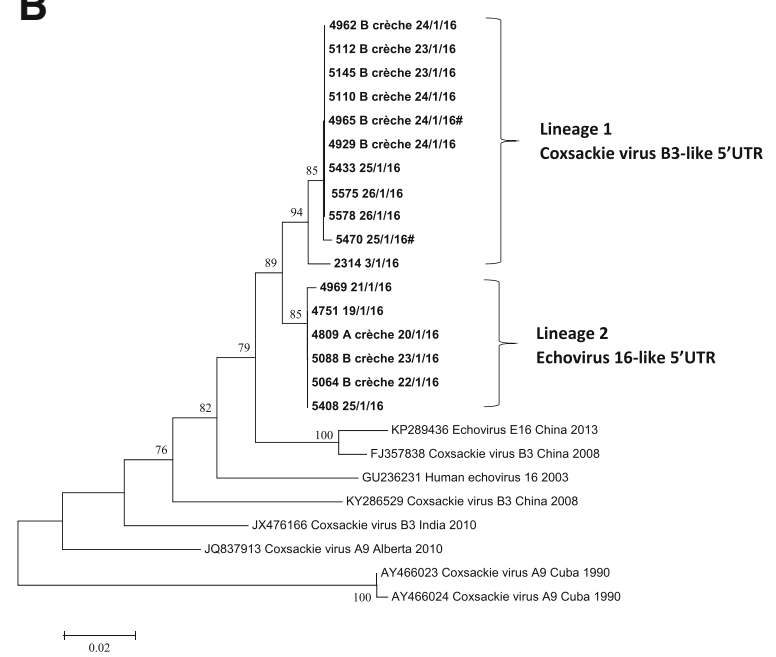

Fig. 3 (a) VP1 and (b) 5'UTR phylogenetic trees of aseptic meningitis cases associated with CVA9

this outbreak three crèches with aftercare facilities were affected, recording numerous cases of aseptic meningitis. Although these facilities were not closed, in order to contain the outbreak, local health authorities initiated daily hand hygiene practise training for staff and parents, and children suspected of being ill were kept at home.
While the primary route of transmission of $\mathrm{HEV}$ is via the faecal-oral route, other transmission routes including respiratory droplet spread and indirect spread through water- borne sources could also have played a role, although none of these were investigated in this study [29-31].

There are numerous reports of CVA9 as a significant causal agent of aseptic meningitis from around the world, including Japan (1961) [32], Northern Ireland (1970) [33], Poland (1974) [34, 35], Cuba (1990-1991) [36], Argentina (2007-2008) [37], Switzerland [38], Canada (2010) [39, 40], China (2006-2012) [41] as well South Africa [14]. Consistent with our study, the majority of cases occurred in children under 10 years of age.

Reasons for large outbreaks of specific HEV serotype-associated aseptic meningitis are not clear. Herd immunity plays an important role, and a decline in immunity to a particular serotype is either due to the emergence of a new serotype lineage or the re-emergence of a lineage from the past to which the population is susceptible. In addition, HEVs are subject to recombination and genetic divergence and these events may change the virus antigenicity, thus changing the immune response and also the HEV circulation patterns [42, 43]. Tracking of circulating HEV serotypes in South Africa has only recently recommenced with the growing interest in understanding serotype prevalence over time and clinical association. Hellferscee et al. [44] identified 33 different serotypes circulating over a 3-year period (2012-2014) in respiratory samples with echovirus 30 , coxsackie virus B5 and enterovirus D68 most prevalent, and 3 cases of CVA9 detected. Unpublished data from Cape Town from 2014 to 2017 showed 38 different serotypes circulating in respiratory samples with different serotypes predominating in each year (Smuts, unpublished). Similarly, over the same period, more than 10 different serotypes were detected in the CSF of patients with central nervous system disease each year, with echovirus 9, echovirus 30 and CVA9 most commonly found (Smuts, unpublished). As historic sequence data of the VP1 region of CVA9 from South Africa is not available, it is not possible to determine if this outbreak was a result of an increase in the number of susceptible individuals in the population or the emergence of an immune escape mutant. However, it can be speculated that the homology of the outbreak virus with that found in Cape Town and Johannesburg early in 2015 would suggest that the virus had been in circulation for a while and that herd immunity may have dropped to below a critical threshold.

Nucleotide sequence and phylogenetic analysis of the 5'UTR and VP1 regions of CVA9 showed the co-circulation during this outbreak of 2 distinct lineages. Lineage 1 included the earliest aseptic meningitis cases detected on 31st December 2015, 3rd and 15th January 2016. This lineage also clustered with CVA9 from respiratory samples 
A

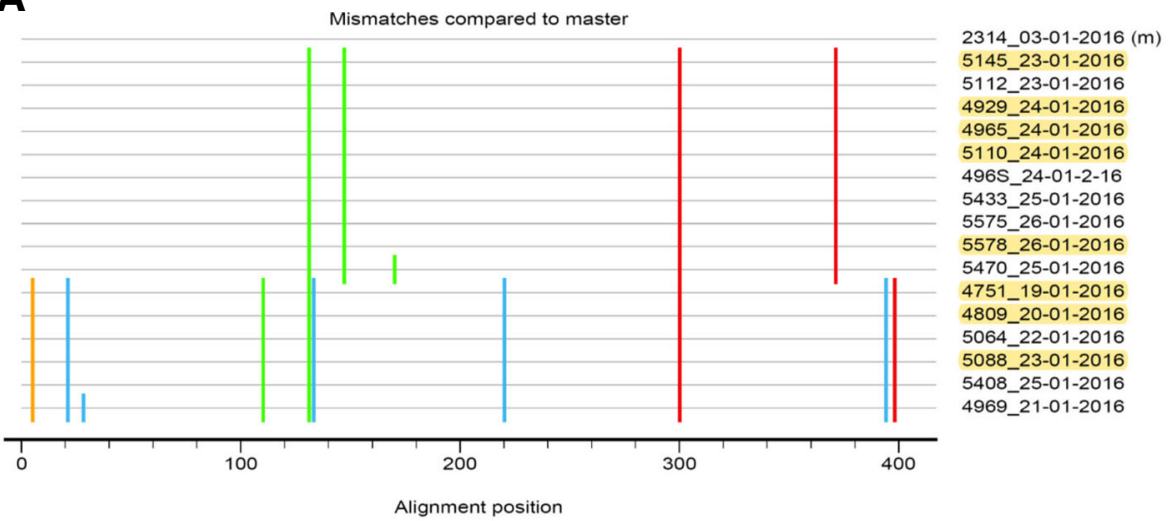

B

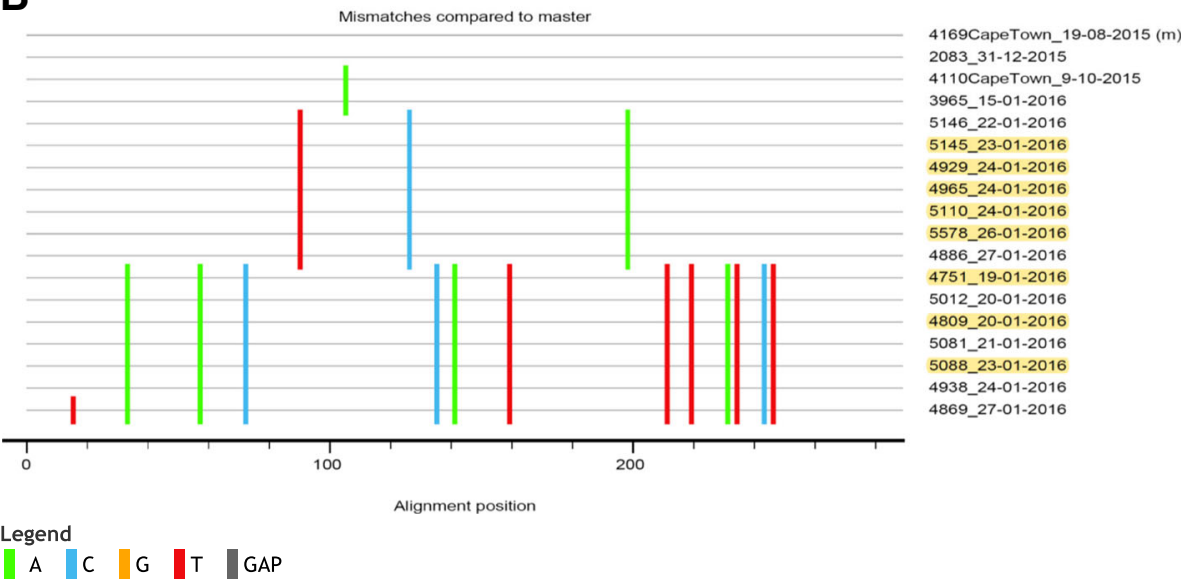

Fig. 4 Highlighter plot of the 5'UTR (a) and VP1 (b) nucleotide sequences of CVA9-positive aseptic meningitis cases by similarity. Highlighted sequences are common to both data sets

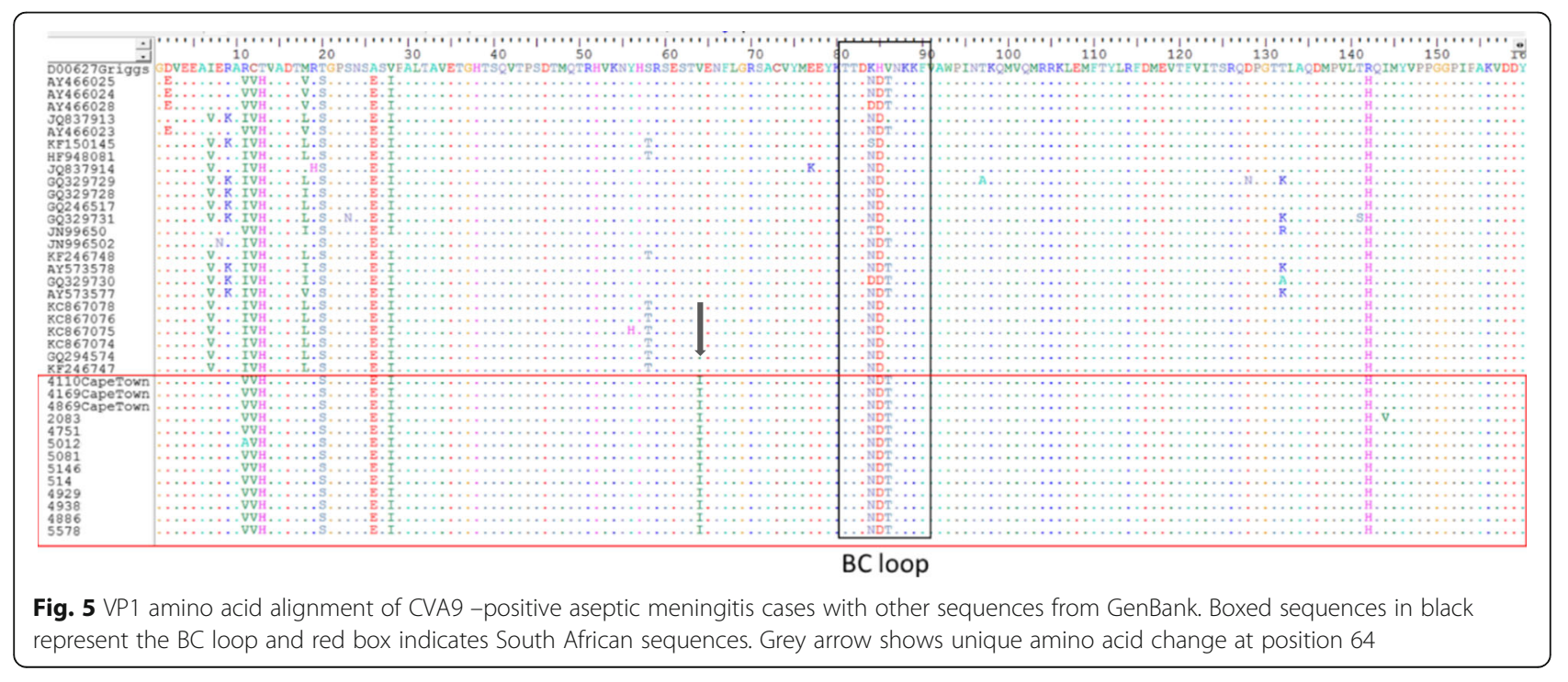


collected in Cape Town and Johannesburg earlier in 2015. The outbreak virus however, formed a distinct cluster within this lineage.

The VP1 amino acid sequence, on the other hand, was identical in both the outbreak viruses as well as viruses from Cape Town earlier in 2015. All had a unique isoleucine at position 64 which was not present in any of the reference sequences from GenBank, including the prototype Griggs strain. There was also an amino acid substitution in the hypervariable BC loop with a threonine replacing a valine. The VP1 capsid protein is 292 amino acids in length with many of the immunodominant serotype-specific epitopes located in the exposed BC loop (amino acid 82-93) [45, 46]. Although valine and threonine are structurally very similar, the substitution at this important neutralizing immunogenic site may have changed the conformation of the $\mathrm{BC}$ loop, thus altering the antigenicity. This may account for the increased susceptibility in this population. While the amino acid sequence of the VP1 gene was the same, the 2 lineages had distinct (synonymous) signature nucleotide substitutions in both 5'UTR and VP1 genes.

There are some limitations to this study. Firstly, the number of outbreak-related cases is likely under-reported. In the early stages of the outbreak all children with clinical manifestations suggestive of aseptic meningitis were routinely admitted to hospital where lumbar punctures were performed. However, as news of this outbreak spread it is possible that clinicians were familiar with the syndromic manifestations and opted for out-patient management of milder cases and not subject them to lumbar punctures. Anecdotally it was reported that many adults presented with a similar constellation of symptoms, but no CSF was collected and they were treated symptomatically. In this report CSF was available from only 1 adult, the father of a child attending one of the affected crèches. Attempts were made to obtain stool samples from adults presenting with compatible symptoms where the clinician had opted not to collect CSF, but no samples were received. Secondly, medical history and additional clinical data which would have provided additional information on the clinical course of aseptic meningitis was not available. A third limitation was the use of the 5'UTR for serotyping in some cases. As mentioned previously this is not the ideal target for serotyping, but where VP1 amplification failed, sequencing of this region did provide useful phylogenetic data. The 5'UTR sequence data showed that in the weeks preceding the outbreak echovirus 6,15 and 30 were circulating in the Mossel Bay area. Further, correlation of the VP1 CVA9 sequence data with the 5'UTR results showed that there were 2 distinct lineages of this virus circulating during the outbreak. However, despite these shortcomings the study identified CVA9 as the causal agent in this large outbreak of aseptic meningitis.

\section{Conclusions}

Our study identified CVA9 as the pathogen responsible for a large outbreak of aseptic meningitis, with the co-circulation of 2 distinct lineages.

\section{Additional files}

Additional file 1: Fasta-formatted file of the 5'UTR sequences used in the identification of HEV serotypes and in the construction of the phylogenetic tree and analysis of the outbreak. (TXT $10 \mathrm{~kb}$ )

Additional file 2: Fasta-formatted file of the VP1 sequences used in the identification of HEV serotypes and in the construction of the phylogenetic tree and analysis of the outbreak. (TXT $11 \mathrm{~kb}$ )

\section{Abbreviations}

5'UTR: 5' untranslated region; CSF: Cerebrospinal fluid; CVA9: Coxsackie virus A9; CVB3: Coxsackie virus B3; E16: Echovirus 16; HEV: Human enterovirus; RTPCR: Reverse transcription polymerase chain reaction; VP1: Viral capsid protein 1; VP2: Viral capsid protein 2

\section{Acknowledgements}

We thank Drs. Orienka Hefferscee and Florette Treurnicht from the National Institute for Communicable Diseases (NICD) for generously allowing us to use their CVA9 sequence data. We also thank the NHLS Virology Molecular Diagnostic staff at Groote Schuur Hospital for RNA extraction of CSF samples.

\section{Author contributions}

HS, JT, SK and DH conceived and designed the study. HS performed the experiments, analysed the data and drafted the manuscript. SC and DB participated in the study investigation and provide the samples and clinical data. DH, JT and SK critically revised the manuscript. All authors have read and approved the final manuscript.

\section{Ethical statement}

This study was approved by the University of Cape Town Human Research Ethics committee (HREC), HREC REF: 079/2015 and conforms to the 2013 Declaration of Helsinki. The diagnosis of enterovirus in all cases was covered by verbal informed consent to CSF collection and diagnostic testing, with this consent being given to their clinician by patients and/or parents/ guardians of patients. These samples were serotyped as part of a broader 3 year project (Molecular surveillance of non-polio enteroviral infections in patients with viral meningitis and respiratory illness, 2015-2017) for which the HREC did not require specific consent for further investigations on diagnosed enteroviruses.

\section{Funding}

This study was funded by the Poliomyelitis Research Foundation grant number $15 / 28$. The funders had no role in the design of the study and collection, analysis, and interpretation of data and in writing the manuscript.

\section{Availability of data and materials}

The datasets generated and/or analysed during the current study are available in the GenBank repository under accession numbers MH558061 MH558083 and MH558084 - MH558112. (https://www.ncbi.nlm.nih.gov/ genbank/). All data generated or analysed during this study are also included in this published article [and its supplementary information files].

\section{Consent for publication}

Not applicable.

Competing interests

The authors declare that they have no competing interests.

\section{Publisher's Note}

Springer Nature remains neutral with regard to jurisdictional claims in published maps and institutional affiliations. 


\section{Author details}

${ }^{1}$ Division of Medical Virology, Department of Pathology, Faculty of Health Sciences, University of Cape Town, South Africa and the National Health Laboratory Service, Anzio Road, Observatory, Cape Town 7925, South Africa. ${ }^{2}$ Life Bay View Private Hospital, Ryk Tulbach Street \& Alhof Drive, De Nova, Mossel Bay 6506, South Africa. ${ }^{3}$ Centre for Enteric Diseases, National Institute for Communicable Diseases, 1 Modderfontein Road, Sandringham, Johannesburg 2130, South Africa. ${ }^{4}$ PathCare George Laboratory, 1 Gloucester Avenue, George 6529, South Africa.

\section{Received: 16 August 2018 Accepted: 19 December 2018} Published online: 29 December 2018

\section{References}

1. Pallansch MA, Oberste MS, Whitton JL. Enteroviruses: polioviruses, coxsackieviruses, echoviruses, and newer enteroviruses. In Knipe DM, Howley P, editors. Fields virology 2. 6th ed. Lippincott Williams \& Wilkins; 2013

2. Pons-Salort M, Parker EP, Grassly NC. The epidemiology of non-polio enteroviruses: recent advances and outstanding questions. Curr Opin Infect Dis. 2015;28:479-87.

3. Julbert B and Lipton HL. Enterovirus/Picornavirus infections. Chapter 18 in Handb Clin Neurol, Vol. 123 (3rd series) Neurovirology A.C. Tselis and J. Booss, Editors 2013.

4. Rotbart HA. Viral meningitis. Semin Neurol. 2000;20:277-92.

5. Bailly J-L, Be'Guet A, Chambon M, Henquell C, Lafeuille HP. Nosocomial transmission of echovirus 30: molecular evidence by phylogenetic analysis of the VP1 encoding sequence. J Clin Microbiol. 2000;38:2889-92.

6. Romero JR. Reverse-transcription polymerase chain reaction detection of the enteroviruses. Arch Pathol Lab Med. 1999;123:1161-9.

7. Knowles NJ, Hovi T, Hyypiä T, King AMQ, Lindberg AM, Pallansch MA, Palmenberg AC, Simmonds P, Skern T, Stanway G, Yamashita T, Zell R. Picornaviridae. In: King AMQ, Adams MJ, Carstens EB, Lefkowitz EJ, editors. (ed), virus taxonomy: classification and nomenclature of viruses: ninth report of the international committee on taxonomy of viruses. San Diego, CA: Elsevier; 2012. p. 855-80.

8. Oberste MS, Maher K, Kilpatrick DR, et al. Molecular evolution of the human enteroviruses: correlation of serotype with VP1 sequence and application to picornavirus classification. J Virol. 1999;73:1941-8.

9. Picornaviridae.com. www.picornaviridae.com/enterovirus/enterovirus. Accessed 9 March 2018.

10. Caro V, Guillot S, Delpeyroux F, Crainic R. 2001. Molecular strategy for "serotyping" of human enteroviruses. J Gen Virol. 2001;82:79-91.

11. Ramers C, Billman G, Hartin M, et al. Impact of a diagnostic cerebrospinal fluid enterovirus polymerase chain reaction test on patient management. JAMA. 2000;283:2680-5.

12. Norder H, Bjerregaard L, Magnius L, Lina B, Aymard M, Chomel J-J. Sequencing of "untypeable" enteroviruses reveals two new type, EV-77 and EV-78, within human enteroviruses type B and substitutions in the BC loop of the VP1 protein for known types. J Gen Virol. 2003;84:827-36.

13. Lee BE, Davies HD. Aseptic meningitis. Curr Opin Infect Dis. 2007;20:272-7.

14. Mclntyre JP, Keen GA. Laboratory surveillance of viral meningitis by examination of cerebrospinal fluid in Cape Town, 1981-9. Epidemiol Infect. 1993;111(2):357-71.

15. Yeats J, Smuts H, Serfontein CJ, Kannemeyer J. Investigation into a school enterovirus outbreak using PCR detection and serotype identification based on the 5' non-coding region. Epidemiol Infect. 2005;133(6):1123-30.

16. Smuts $\mathrm{H}$, Hardie D. Phylogenetic identification of human enteroviruses associated with clusters of meningitis in 2009 and 2010. Commun Dis Surv Bull. 2010;8:55-7.

17. Wolfaardt M, Buchner A, Myburgh M, Avenant T, du Plessis NM, Taylor MB. Molecular characterization of enteroviruses and clinical findings from a cluster of paediatric viral meningitis cases in Tshwane, South Africa 20102011. J Clin Virol. 2014;61:400-5.

18. McWilliam Leitch EC, Harvala H, Robertson I, Ubillos I, Templeton K, Simmonds P. Direct identification of human enterovirus serotypes in cerebrospinal fluid by amplification and sequencing of the VP1 region. $J$ Clin Virol. 2009:44:119-24.

19. McLeish NJ, Witteveldt J, Clasper L, McIntyre C, McWilliam Leitch EC, Hardie A, et al. Development and assay of RNA transcripts of enterovirus species a to $D$, rhinovirus species a to $C$, and human parechovirus: assessment of assay sensitivity and specificity of real-time screening and typing methods. J Clin Microbiol. 2012:50(9):2910-7.

20. Basic Local Alignment Search Tool. https://blast.ncbi.nlm.nih.gov/Blast.cgi. Accessed 15 January 2018

21. Enterovirus Genotyping Tool Version 0.1. http://www.rivm.nl/mpf/ enterovirus/typingtool. Accessed 20 November 2017.

22. Pickett BE, Sadat EL, Zhang Y, Noronha JM, Squires RB, Hunt V, et al. ViPR: an open bioinformatics database and analysis resource for virology research. Nucleic Acids Res. 2012;40(Database issue):D593-8.

23. Hall TA. BioEdit: a user-friendly biological sequence alignment editor and analysis program for windows 95/98/NT. Nucl acids Symp. Ser. 1999;41:95-8.

24. Tamura K, Stecher G, Peterson D, Filipski A, Kumar S. MEGA6: Molecular Evolutionary Genetics Analysis version 6.0 Mol Biol Evol 2013; 30(12): 2725-2729.

25. HIV Database Tools. https://www.hiv.lanl.gov/content/sequence/HIV/ HIVTools.html. Accessed 16 March 2018.

26. Chan JH, Law CK, Hamblion E, Fung H, Rudge J. Best practices to prevent transmission and control outbreaks of hand, foot, and mouth disease in childcare facilities: a systematic review Hong Kong Med J. 2017;23(2):177-90.

27. Mohle-Boetani JC, Matkin C, Pallansch M, Helfand R, Fenstersheib M, Blanding JA, Solomon SL. Viral meningitis in child care Centre staff and parents: an outbreak of echovirus 30 infections. Public Health Rep. 1999; 114(3):249-56.

28. Helfand RF, Khan AS, Pallansch MA, Alexander JP, Meyers HB, DeSantis RA, Schonberger LB, Anderson LJ. Echovirus 30 infection and aseptic meningitis in parents of children attending a child care Centre. J Infect Dis. 1994;169(5): 1133-7.

29. Faustini A, Fano V, Muscillo M, Zaniratti S, La Rosa G, Tribuzi L, Carlo A. Perucci CA. 2006. 297 An outbreak of aseptic meningitis due to echovirus 30 associated with attending school and swimming in pools. Intern J of Infect Dis 2006; 10: 291-297.

30. Dente FA, Blanchollun E, Delicnierex A, Flamen P. 1974. Coxsackievirus A16 infection from lake water. JAMA. 1974;228:1370-1.

31. Kee F, McElroy G, Steward D, Coyle P, Watson J. 1994. A community outbreak of echovirus infection associated with an outdoor swimming pool. J Public Health Med. 1994;16:145-8.

32. Nakao T, Nitta T, Miura R, Ogata K, Kume T, Nobuta K, Hinuma Y. Clinical and epidemiological studies on an outbreak of aseptic meningitis caused by Coxsackie B5 and A9 viruses in Aomori in 1961. Tohoku J Exp Med. 1964; 83:94-102.

33. Connolly JH, O'Neill HJ. Coxsackie A9 virus outbreak in Northern Ireland during 1970. Ulster Med J. 1971;40(2):146-50.

34. Kocielska W, Gruszecka A. An epidemic of meningitis caused by Coxsackie A9 virus in the City of Wrocław in 1974. Przegl Epidemiol. 1975:29(4):431-2.

35. Holówka A, Gawron H, Janowicz M, Wysoczyńska H, Zabicka J. An epidemic of meningitis in the Kwidzyń County caused by Coxsackie A9 virus. Przegl Epidemiol. 1975;29(4):433-7.

36. Bello M, Más Lago P, Palomera R, Castillo A, Amín N, Acosta B, et al. Enterovirus meningoencephalitis in the last 5 years. Rev Cubana Med Trop. 1996;48(2):118-22.

37. Farías A, Cabrerizo M, Ré V, Glatstein N, Pisano B, Spinsanti $L$, et al. Molecular identification of human enteroviruses in children with neurological infections from the central region of Argentina. Arch Virol. 2011;156(1):129-33.

38. Butsch R, Tapparel C, Keller P, Herzog K, Krause M, Wunderli W, et al. Family outbreak of an infection with a recombinant Coxsackie a virus in eastern Switzerland. Infection. 2013;41:231-5.

39. Pabbaraju K, Wong S, Chan EN, Tellier R. Genetic characterization of a Coxsackie A9 virus associated with aseptic meningitis in Alberta, Canada in 2010. Virol J. 2013;10:93-101.

40. Peci A, Winter A-L, Eshaghi A, Marchand-Austin A, Olsha R, Lombardi N, et al. Coxsackie viruses in Ontario, January 2005 to December 2011. International J Infect Dis. 2014;25:136-41.

41. Cui A, Yu D, Zhu Z, Meng L, Li H, Liu J, et al. An outbreak of aseptic meningitis caused by coxsackievirus A9 in Gansu, the People's Republic of China. Virol J. 2010;7:72-80.

42. Santti J, Hyypiä T, Kinnunen L, Salminen M. Evidence of recombination among enteroviruses. J Virol. 1999;73(10):8741-9.

43. Oberste MS, Peñaranda $S$, Pallansch MA. RNA recombination plays a major role in genomic change during circulation of coxsackie B viruses. J Virol. 2004;78(6):2948-55. 
44. Hellferscee O, Tempia S, Walaza S, Variava E, Dawood H, Wolter N, et al. Enterovirus genotypes among patients with severe acute respiratory illness, influenza-like illness, and asymptomatic individuals in South Africa, 20122014. J Med Virol. 2017;89(10):1759-67.

45. Norder H, Bjerregaard L, Magnius LO. Homotypic echoviruses share amino terminal VP1 sequence homology applicable for typing. J Med Virol. 2001;63(1):35-44.

46. Reimann BY, Zell R, Kandolf R. Mapping of a neutralizing antigenic site of Coxsackievirus B4 by construction of an antigen chimera. J Virol. 1991;65(7):3475-80.

- fast, convenient online submission

- thorough peer review by experienced researchers in your field

- rapid publication on acceptance

- support for research data, including large and complex data types

- gold Open Access which fosters wider collaboration and increased citations

- maximum visibility for your research: over $100 \mathrm{M}$ website views per year

At BMC, research is always in progress.

Learn more biomedcentral.com/submissions 